\title{
The use of on-line computers in psychobiology
}

\author{
MICHAEL CASSADY \\ University of California, Irvine, California 62662 \\ MICHAEL M. PATTERSON \\ Kirksville College of Osteopathic Medicine, Kirksville, Missouri 63501 \\ RICHARD ROEMER \\ Eastern Pennsylvania Psychiatric Institute, Philadelphia, Pennsy/vania 19129
}

\begin{abstract}
This paper examines several areas in the lise of laboratory computers in psychobiology, specificaily how they are being used, the problems in languages and software, in interfacing computers to experimental configurations, and in the hardware involved. The paper defines the experimental tasks and data requirements which tend to distinguish computer usage in physiological research from other areas of psychology and the tasks which absolutely necessitate the use of a computer and in what mode. Finally we present our views of the dangers of computer use and misuse and make our own subjective evaluation of how well computers are living up to their end of the bargain, how well scientists are doing at their end, and where we should go from here.
\end{abstract}

Laboratory computers have been in use since the late 1950s. The history has been well summarized by, anong others. Sidowski $(1970,1972,1975)$ and Aaronson and Grupsmith in this issue. We surveyed The Journal of Comparative and Physiological Psychology, Physiology and Behavior, and Electroencephalography and Clinical Neurophysiology for the past 2 years to record the uses of laboratory computers in psychobiology. In such a survey. the information often reflects nork begun up to 2 or 3 years earlier, so current trends may not be reflected accurately. In these journals, about 1,452 articles were published between July 1973 and July or September 1975. The results of the survey are shown in Table 1 . It is apparent that the use of computers was much greater in studies reported in EEG and Clinical Neurophysiology. This undoubtedly reflects the homogeneity of articles in the journal, which reports work very amenable to computer analysis. About $3^{\sigma_{0}}$ of all articles in Physiology and Behavior and Journal of Comparative and Physiological Psychology used computers, while $24 \%$ of the articles in $E E G$ and Clinical Neurophysiology used them. Note that any use of a computer was included in the survey, not only laboratory computers, but larger facilities as well. The survey was not limited to laboratory systems. Those applications in which the computer recorded and partially reduced the data were counted in a

Preparation of this paper was supported in part by Grant I-RO I NS 1004 from the NINCDS to MMP. Requests for reprints should be sent to Michael M. Patterson, Department of Physiology. Kurkwille College of Osteopathic Medicane. Kirksville. Missouri 6.35011. Ihos paper was presented at the Fifth Annual National Conference on the Use of On-Line Computers in Psychology. L'nusersals of Colorato. November 5. 1975. data-acquisition category. Only if a statistical analysis was performed was the computer counted in a data analysis category. It is, of course, possible that in some cases larger computer facilities were used for data analysis but not reported in the study.

It is evident from Table 1 that in studies of EEG and related phenomena. computer usage is primarily toi data acquisition and analysis: proportionally nore use ol computers for experimental control occurred in studies published in the other tuo more traditionally psichological journals. The most striking result of the stud. however. is the relatively limited use of computers for any aspect of experimentation, especially that presented in JCPP and Physiology and Behavior. At least for the studies published during this 2-year period, computers seem to play a much smaller role than might be expected from the excitement generated by availability of these machines.

\section{HARDWARE AND SOFTWARE CONSIDERATIONS IN PSYCHOBIOLOGY}

Harduare and software considerations for on-line computers in psychobiology are not unique to the area. The typical computer facility for psychobiological experimentation contains most of the elements familiar to other computer applications. One of the highest priority hardware items is a programmable clock, which enables the experimenter to control the microsecond intervals necessary for data acquisition. In addition to the clock, analog-digital converters and Schmitt triggers are desirable to convert raw analog signals in to digital data.

There are at least four characteristics of 
Table 1

Computer Reports in Journals

\begin{tabular}{|c|c|c|c|c|c|c|c|}
\hline \multirow[b]{2}{*}{ 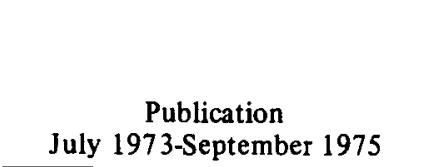 } & \multirow[b]{2}{*}{$\begin{array}{l}\text { Total } \\
\text { No. of } \\
\text { Articles }\end{array}$} & \multirow[b]{2}{*}{$\begin{array}{l}\text { Total No. of } \\
\text { Papers Using } \\
\text { Computers }\end{array}$} & \multirow[b]{2}{*}{ Off-line } & \multicolumn{4}{|c|}{ On-line* } \\
\hline & & & & Total & $\begin{array}{l}\text { Con- } \\
\text { trol }\end{array}$ & $\begin{array}{l}\text { Data } \\
\text { Acqui- } \\
\text { sition }\end{array}$ & $\begin{array}{l}\text { Data } \\
\text { Analy } \\
\text { sis }\end{array}$ \\
\hline \multicolumn{8}{|l|}{ Journal of Comparative and } \\
\hline Physiological Psychology & 614 & $21(3.4 \%)$ & $6(1 \%)$ & $15(2.4 \%)$ & 15 & 14 & 4 \\
\hline Physiology and Behavior & 596 & $15(2.5 \%)$ & $10(1.6 \%)$ & $5(.7 \%)$ & 3 & 5 & 3 \\
\hline EEG and Clinical Neurophysiology & 242 & $58(24 \%)$ & $39(16 \%)$ & $19(8 \%)$ & 3 & 19 & 9 \\
\hline
\end{tabular}

* Subareas will not add to total since, in many cases, the same computer was used for two or three tasks.

psychobiological studies which tend to distinguish them from other types of psychologicai studies.

The tirst is the requirement for relatively high data-sampling rates. Evoked potential studies generally use rates of $1 \mathrm{KHz}$ per channel. Single and multiple unit studies can require sampling rates in excess of $10 \mathrm{KHz}$. Intracellular studies of synaptic potentials can require up to $50 \mathrm{KHz}$ sampling rates. These high sample rates lead to the second characteristic: many data points are often taken during each experiment. For example: consider a not-too-sophisticated experimental session involving six data channels, each sampled every millisecond for $512 \mathrm{msec}$. If there are 128 trials, this represents 393.216 data points. Even if averages over 32 trials are taken. 12.288 data points/subject/session are generated. Because of the large number of data points. there is a need for mass data storage, and some form of computer facility is needed to analyze the volume of data, either in-house or in a large-scale computing facility, as proposed by Donchin and Heffley (1975). This implies the existence of a method of getting the data into the large-scale facility, generally by compatible magnetic tape. Also implied are funds for computing. and often access to coniputer networks. FORTRAN programs for the entire range of analyses applicable to physiology are presented in such publications as Statistical Package for Social Scientists (SPSS) (Nie, Hadlaihuli, Jenkins, Steinbrenner. \& Bent. 1975) and Cooley and Lohnes (1971). These programs are readily adaptable to the hardware constraints imposed by minicomputers although the array dimensions generally must be made compatible with the available core storage and necessary moditications may include reducing the number of levels of subscripting. Wood, Sette, and Weiss (1975) review metalanguages (e.g., SCAT, SKED. ACT, and INTERACT) and discuss some of the limitations of compilers and metalanguages.

\section{COMPUTER APPLICATIONS IN PSYCHOBIOLOGICAL EXPERIMENTS}

The phases of a typical neurophysiological experiment are not much different than those of other areas: stimulus presentation, data acquisition, and data analysis. Perhaps in only one case is the use of an on-line computer absolutely necessary. That is the case in which response-contingent stimuli are presented. Such a situation requires that the computer interact rapidly with information provided it by the subject and feedback information to the subject for his next response. Other experimental situations and data analyses can often best be handled off-line and may not make good use of the computer's unique features. This does not imply that on-line computer control of data handling in other situations is necessarily undesirable, but rather that in other situations, the use of an on-line computer should be done with care. Often there exist viable and less expensive, albeit less flashy, alternatives to computer use which may be more efficient. However, in all three phases of an experiment there are valid uses for computers which would be difficult, if not impossible, to instrument by other means.

\section{Stimulus Presentation}

Response-contingent situations are exemplitied by such paradigms as instrumental conditioning procedures (Fox \& Rudell, 1969; Weiss \& Laties, 1965), biofeedback training in psychophysiology (Schwartz, 1974), and other types of closely coupled stimulus-response-stimulus sequences (Roemer, 1975). A fine example of the use of a minicomputer for visual stimulation is the experimental series by Spinelli and associates (e.g.. Spinelli, 1967; Spinelli, Hirsh, Phelps, \& Metzler, 1972). Here a contrasting disk on a screen is moved across the visual field by the computer which simultaneously counts the number of single neuronal discharges per .5-deg visual segments. In this manner, the visual receptive fields of neurons have been systematically mapped in adult cats and compared to the visual pattern experienced as developing kittens.

The computer is used also to control voltage-controlled oscillators (VCO) to determine auditory tuning curves of neurons. The frequencies generated in this way by the VCO can be a systematic 
sheep over a frequency range, or a randomized presentation of frequencies to evaluate tuning curves over the frequency range.

An excellent example of the use of computers in contingent stimulus presentation is seen in a study by Fox and Rudell (1970) and in a similar study by Rosenfeld. Rudell, and Fox (1969). In these studies, cats and humans were instrumentally rewarded for alterations in a selected portion of an evoked response to light or tone. In each case, the computer uas programmed to calculate the amplitude of a preselected portion of the secondary evoked potential and to present a reuard if the amplitude was $1 \mathrm{SD}$ higher (or lower) than the average of previous responses. In this way, progressive shifts in response amplitude were produced over trials. In this case, the computer $w$ as absolutely necessary to the study due to the constantly changing criteria being used for reintorcement.

I hese are some of the modes of stimulus generation made possible by the computer which would be difficult or impossible to produce by other means. Howerer, it appears that laboratory computers have not been used as extensively in stimulus presentation as mal have been promised. Ihis may be a stronger comment on the experimental questions being asked than on the capability of the machines.

\section{Data Acquisition and Analysis}

In the psychobiological laboratory, it is in data acquisition and analysis that the computer has apparently come into its own. At this point, our discussion extends beyond on-line applications to include digitization of physiological data, which is played back from original AM and FM magnetic tapes. There are several advantages to such off-line analyses. one of which is the more efficient use of computer time. if contingent stimuli are not required. This is particularly true where stimuli are presented with varying times between trials. During these intertrial intervals with the machine on line. it generally must sit idly by waiting for the next trial. By stopping the tape recorders during the intertrial intervals, the idle times are eliminated during the playback. which results in data digitization with much less absolute computer time. In addition, problems of computer dountime during a lengthy experimental session are avoided. The data may then be replayed several times through the computer to analyze several different sets of information. such as (1) slow wave analysis for EEG frequency components, (2) slow Wave analysis for evoked potentials. (3) neural spike rates. (4) amplitude windows of neural spikes which separate large unit populations from smaller-sized units. (5) analysis of the interspike intervals (single units), or (6) a change in the time constraints of any of the above categories.

It is evident that data reduction and analysis can often be best and most efficiently completed off line. In the past, large computers have often been used for this task because of their ability to digest large quantities of information in a short time. The chief drau back to this solution has been cost, especially if a special transmission line is used to convey the data from one machine to the other. For these reasons, investigators have often opted to analyze data in their ou n laboratory minicomputer off line during inactive periods of the day or night. This is not necessarily an efficient use of the machine since computation can be quite slom. This is oftset. how ever, by the low cost and the fact that the turnaround times are about the same. As large computer costs drop and as computer connect-time costs decrease. more investigators will probably reverse this trend. utilizing the large computer for its number-crunching capabilities.

\section{Problems of Computer Dependency}

Several dangers and problems are attendant to the use of any laboratory computer, perhaps especially in psychobiology. Like many other technological creations. the computer is a tool to be utilized in an effective way to obtain answers to important scientific questions. not as an end or as an omnipotent entity that determines the clrcumstances under which the questions can be asked. The issue here is not whether computers are domg the things promised, but whether investigators are intelligently utilizing the equipment. In many cases, the experiments can be controlled or datta acquired and analyzed by means other than a computer and in a more efficient manner. When computers are used in such cases. the danger increases that the computer hardware or softu are will dictate the terms of the experimental procedure. This particularly insidious aspect of the laboratory minicomputer has a tendency to "steal power from the experimenter." It then becomes too easy to design experiments which are compatible with the existing hardware and sollware rather than to develop the configurations necessary to adequately deal with the experimental question. In this case, the potential of the computer is abrogated.

One discomforting trend in psychobiology seems to be an increasing reliance, on the part of investigators, on technical staffs and products which are not fully understood. During the developmental years of electrophysiology, investigators constructed their own equipment since none was commercially available. The advent of integrated circuitry has made the problems associated with the construction of electronic apparatus immeasurably easier, yet the trend to reliance on technical support appears to have increased.

\section{Future Trends}

Future trends in the computer field are sure to result in even greater changes in neurophysiological 
research than have already occurred, primarily because microcomputers will be available in large quantitites at a substantial reduction. Even today, a microprocessor and $8 \mathrm{~K}$ of core can be purchased for only a few hundred dollars (Robinson, 1974). Much of the present laboratory equipment will be replaceable with off-the-shelf items. We expect to sce microcomputers extensively used in data preprocessing or signal conditioning for such tasks as counting neural discharges, performing analog-todigital and digital-to-analog conversions, doing spectral analyses, handling stimulation presentations and for mass storage of the data. The minicomputer would be used for analysis functions as well as to prepare data for transmission to the larger computer. Alternatively, hand-carried tapes or disk packs prepared by the mini would not be an unacceptable possibility. The role of the large-scale systems would be twofold. First, they would perform cross-compiling functions so that the researcher can generate programs for the minisystem on the maxi, taking advantage of the elegant text editing and formatting aids which reside there. Second, they would increasingly be used for routine large-scale data analysis as other costs decline.

Programs that are produced on the maxis for specitic minis could reside in public files, permitting other scientists with similar systems to use them. This would reduce the overall cost of repetitious software development nou borne by many grants. A secondary, but not insigniticant. by-product would be an automatic standardization of data-storage formats. Currently, the lack of standard data formats within the field essentially precludes the convenient and orderly sharing of programs among scientists, even with identical machinery. Such programs in a public file could then be loaded into the minisystem via a time-sharing connection. The experiment would then be conducted by the micro-mini configuration, with preliminary data reduction accomplished by the microsystem which would then access the minisystem and transfer the reduced data to permanent files for more extensive analysis. Until the cost of high-speed data lines decreases, the interactive transfer of all the data from an experiment is probably not reasonable in terms of either time or costs.

In summary, we foresee increasing application of integrated circuitry and minicomputers in the experimental situation, coupled with an increasing use of large-scale computer analyses of psychobiological data. This will lead to more general acceptance of computers and a more sophisticated level of questions being asked of such on-line systems than are now being formulated in most laboratories.

\section{REFERENCES}

Coleman. P. D., West. M. J., \& Wyss, U. R. Computer-aided quantitative neuro-anatomy. In B. Weiss (Ed.). Digital computers in the behavioral laboraton. New York: Appleton-Century-Crotts. 1973.

COOley. W. M., \& LoHnes, P. R. Multwariate data analysts. New York: Wiley. 1971.

Donchin. E., \& Heffley, E. Minicomputers in the signal averaging laboratory. American Psychologist. 1975, 30, 299-312.

Fox. S. S.. \& Rudell. A. P. Operant controlled neural event. Functional independence in behavioral coding by early and late components of visual cortical evoked response in cats. Journal of Neurophysiology, 1970, 33, 548-561.

Nie. N. H.. Hadialhuli. C.. Jenkins. J.. Steinbrenner. K.. \& BENT. D. SPSS: Statistical package for the social sciences. New York: McGraw-Hill, 1975.

Robinson, A. L. Computers: First the maxi, then the mini, now it's the micro. Science, 1974. 186, 1102-1104.

Roemer. R. A. Some interactive computer applications in a phistological psychology laboratory. American Psychologist. $1975,30.295-298$.

Rosenfeld, J. P.. Rudell, A. P.. \& Fox. S, S. Operant control of neural events in humans. Science, 1969, 165, 821-823.

Schwartz. G. E. Toward a theory of voluntary control of response patterns in the cardiovascular system. In P. A. Obrist. A. H. Black. J Brener, \& L. V. DiCara (Eds.), Contemporary trends in cardiovusculur psychophysiology. Chicago: Aldine, 1974.

Sidowski. J. B. Minicomputers. Behavior Research Methods \& Instrumentution. 19-0. 2. 267-286.

Sidow SkI. J. B. Various uses of minicomputers in psychology. Behavior Research Methods \& Instrumentation, 1972, 4, 43-50.

Sidowski. J. B. Instrumentatıon and computer technology: Applications and influences in modern psychology. American Psychologist, 1975, 30, 191-196.

SPINELLI. D. N. Receptive field organization of ganglion cells in the cat's retina. Experimental Neurology, 1967. 19. 291-315.

Spinelli. D. N.. Hirsh, H, U. B.. Phelps, R. W.. \& Metzler. J. Visual experience as a determinant of the response characteristics of cortical receptive tields in cats. Experimental Brain R'surarch, 1972. 15. 289-306.

Robinson. Arthur L. Computers: First the maxi, then the mini. now il's the micro. Scance, 1974, 186. 1102-1104.

Weiss, B.. \& Laties, V. G. Reinforcement schedule generated by an on-line digital computer. Sct'nce. 1965, 148, 658-661.

Wood, R. W.. Sette, W. F.. \& Weiss, B. Interfacing the experimenter to the comiputer: Languages for psychologists. American Psichologist. 1975, 30. 230-238. 